\title{
LAS HISTORIAS DEL TEATRO ARGENTINO
}

Osvaldo Pellettieri

UBA-CONICET

\begin{abstract}
RESUMEN
La crítica y la investigación teatral latinoamericana ha sido severamente cuestionada. Por supuesto, la crítica y la investigación teatral argentina no escapan a ese cuestionamiento.

En este trabajo trataremos tres etapas de nuestra historiografía teatral, centrándonos especialmente en los trabajos de Mariano G. Bosch (1865-1948), publicados entre 1904 y 1929 y que abarcan las tres primeras décadas del siglo; los de Ernesto Morales (1890-1959), Raúl H. Castagnino (1914-1998), Arturo Berenguer Carisomo (1905-1992) y Luis Ordaz (1912), publicados en la década del cuarenta, y finalmente a la realización de una Historia del Teatro Argentino que, bajo nuestra dirección, se está llevando a cabo en el GETEA, Área de Investigación Teatral del Instituto de Historia del Arte Argentino y Latinoamericano de la Facultad de Filosofía y Letras de la Universidad de Buenos Aires.

En todos los casos, tratamos de esclarecer los presupuestos metodológicos de los que parten los investigadores y señalar sus logros y los reparos que a nuestro juicio merecen, pero sin dejar de reconocer la importancia que tuvieron, y aún tienen, tanto para el conocimiento de nuestro teatro como por el aporte que significan actualmente para los estudios sobre esta materia.
\end{abstract}

\section{PALABRAS - CLAVE}

historiografía teatral, teatro argentino

$\mathbf{S}_{i}$ aceptamos que toda persona que escribe, dirige, lee o presencia un espectáculo teatral es el resultado de un pasado que actúa sobre ella, sea o no consciente de este hecho, conozca o no sus detalles, podemos deducir sin dificultades la categoría de historicidad del teatro. Simultáneamente, el presente de este arte, en cada representación, resignifica constantemente su pasado. Se ha afirmado con insistencia que el panorama crítico teatral latinoamericano no es suficientemente consciente de esta realidad, se ha puesto de manifiesto la ausencia de trabajos importantes, se ha enfatizado la necesidad de concretarlos y lo ineludible que resulta exponer la evolución de nuestra historiografía.

Analizaremos, entonces, tres momentos de nuestra historiografía teatral, poniendo el acento en las denominadas "Historias del Teatro Argentino".

El primer período incluye las tres primeras décadas del siglo. Lo denominamos "impresionista", y a él corresponden los trabajos de Mariano G. Bosch. De sus obras 
seleccionamos tres: Teatro Antiguo en Buenos Aires, Historia del Teatro en Buenos Aires, e Historia de los orígenes del Teatro Nacional, por considerarlas lo más representativo de su concepción para una historia del teatro argentino. Se ha dicho que Bosch es "el primer historiador de nuestro teatro" (De Diego, 6). Creemos que su "impresionismo" implica un período "pre-histórico" en nuestra historiografía, caracterizado por la "falacia afectiva". Su identificación con algunos momentos del teatro argentino y su evidente antipatía por otros, obedecen más a motivos personales que a una estimación crítica. Sus juicios otorgan valor teatral a textos que simplemente le son simpáticos; considera, tácitamente, su relación psicológica, como un elemento básico de su interpretación.

El esfuerzo de Bosch fue, no obstante las objeciones señaladas, una piedra basal para futuros trabajos históricos, especialmente por su afanosa búsqueda de datos y documentación sobre los orígenes de nuestro teatro. Leído hoy, se lo percibe como una aluvional enumeración de estrenos, caracterizada, a veces, por una enorme dispersión y otras por un excesivo detallismo. Más que textos históricos, podrían calificarse de misceláneas, basadas en lo anecdótico y de una excesiva parcialidad. Se observa que no existe en él preocupación por la periodización ni por una mínima metodología.

Emite juicios sobre el teatro de su época y del pasado sin hacer previamente una mínima descripción de los hechos que trata. Exalta lo que nosotros llamamos "teatro gauchesco primitivo" (El amor de la estanciera, Las bodas de Chivico y Pancha) al que conceptúa como "eminentemente nacional" $(1929,17)$, y detesta, en cambio, el teatro de los Podestá por juzgarlo "uruguayo": "Este (Juan Moreira) fue el teatro uruguayo de los Podestá (...) $(1929,40)$. El momento Juan Moreira i lo que sucedió después del 90 i durante casi un decenio, como consecuencia de otras guacherías más o menos vulgares, fue por el contrario un retroceso." (1910, 474)

También denigra el teatro popular de su momento histórico, representado por el sainete criollo, al que considera "caído en la degeneración" $(1929,19)$. Igual posición de disgusto sustenta ante el teatro español: "Los defectos del teatro español son fundamentales, a nuestro modo de ver, i es por esto que siempre, en los siglos, se repiten los mismos errores. Hai mucho ingenio, sobre todo ingenio, bellezas de lenguaje muchas veces, i hermosos conceptos matizando muchas de sus páginas; pero la base en las clásicamente españolas es un error prolongado por espacio de siglo: la fábula inverosímil ó antihumana; casos concretos que nada prueban ni interesan a nadie. I sobre esa base, es evidente que sólo pueden erigirse sombras... sueños... (sic)." $(1904,22)$

Más allá de estos reparos que no debemos radicalizar sino queremos caer en el anacronismo psicológico, podemos afirmar que Bosch realizó en esos años una labor encomiable, fundamentalmente por dos motivos:

1. La enorme cantidad de información que desde ese momento se incluyó en nuestro patrimonio cultural. Esto se puede observar en el trabajo de Artacho, en el cual la "Advertencia" del comienzo, señala la importancia y también las limitaciones del trabajo de Bosch: "Hemos preparado este índice cronológico de noticias, destinados a ofrecer listo y ordenado, aquel venero de información al estudioso..." (328)

2. El hecho mismo de haber escrito libros sobre la historia del teatro nacional, en un momento en que se ponía en duda la realidad de su existencia, fue altamente positivo para su consolidación. Resulta imposible no comparar el trabajo de Bosch con otro texto 
de ese tiempo, la monumental Historia de la Literatura Argentina, de Ricardo Rojas. Igualmente resulta importante destacar que cuando Rojas fundó el Instituto de Literatura Argentina de la Facultad de Filosofía y Letras de la Universidad de Buenos Aires, en 1922, llamó a Bosch a colaborar, y éste dio a conocer textos emparentados con los inicios de la escena argentina ${ }^{1}$.

Tanto los trabajos de Bosch para el teatro, como los de Rojas para nuestra literatura ${ }^{2}$ coinciden en evidenciar la necesidad que sentía la joven sociedad argentina de nacionalizar su cultura. Sin duda estas historias son respuestas al criterio europeísta que dominaba en nuestro país durante los años ochenta del siglo pasado. Se reaccionó indagando los orígenes de nuestro arte en lo argentino, con un enorme optimismo en el futuro (Pellettieri, 1980). La clave de esa posición era recrear nuestra historia cultural. De acuerdo con el nacionalismo sustentado por Rojas, la literatura y el teatro expresan la "conciencia colectiva". Son expresión de la nacionalidad.

El segundo momento se desarrolla en los años cuarenta. En ese período se editan las historias de Ernesto Morales (1944), Luis Ordaz (1946), Arturo Berenguer Carisomo (1947) y Raúl H. Castagnino (1950). Centraremos nuestro estudio en los trabajos de Ordaz y Berenguer Carisomo por considerarlos representantes del "historicismo".

Dentro del panorama de los cuarenta, consideramos que el intento de Morales y su superación por parte de Castagnino, se incluyen dentro de lo que podríamos denominar una "historia de nombres", una opción biográfica propia del siglo XIX. El libro de Ordaz es una "historia de nombres y de hechos", y el trabajo de Berenguer Carisomo una "historia de corrientes estéticas".

Nos referiremos brevemente a las historias de Morales y Castagnino. Morales trabaja a partir de lo cronológico y concreta un resumen sobre estudios anteriores. Los hechos de la realidad histórica son observados a través de un análisis bio-bibliográfico. Los textos teatrales son juzgados a partir de su anécdota, con pocas alusiones a las características y a la evolución de la obra teatral. Las categorías por medio de las cuales divide la materia son contenidistas, relativas en la mayor parte a hechos históricos argentinos o extranjeros ${ }^{3}$. Morales no considera la historia un proceso racionalizador, y su trabajo no se plantea como finalidad determinar y conceptualizar el objeto de su estudio.

Igualmente, podríamos situar los trabajos de Castagnino dentro de lo que denominamos una "historia de nombres", porque aunque presenta notorios avances con relación a Morales, se mantiene dentro de la tipología antes enunciada. Elabora un método basado en una cronología de momentos pregnantes de nuestra historia política, y establece una jerarquía autoral que se basa en los géneros más prestigiosos y en la

\footnotetext{
1 Rojas posibilitó la publicación de 6 tomos de la colección "Orígenes del Teatro Nacional", que contenía versiones críticas de textos fundamentales, prologados por los más destacados investigadores, y otra colección, "Noticias para la Historia del Teatro Nacional", en la que se publicaron monografías sobre autores de nuestro teatro.

${ }^{2}$ Rojas, en su Historia de la Literatura Argentina, "Los gauchescos", dedicó el capítulo XXVIII a "La tradición gauchesca en el teatro" (601-612) y en "Los Modernos", el capítulo XVIII a la "Formación del Teatro Nacional" (497-569).

${ }^{3}$ Por ejemplo: "El teatro de la Colonia", "El teatro y la revolución", "El teatro de las guerras civiles", "El teatro de la Tiranía y la proscripción", "La reconstrucción civil", "Teatro gauchesco", "Teatro moderno", "Teatro contemporáneo".
} 
resonancia de los textos en el medio teatral. Extrañamente para un tipo de teórico como Castagnino, su historia privilegia las categorías políticas por sobre la serie literaria y teatral. Establece las categorías de nacimiento, desarrollo y decadencia para nuestro teatro propias de la historiografía positivista.

Dentro del historicismo podemos situar la historia realizada por Ordaz, que implica una periodización hecha en base a nombres pero también a hechos. ¿Por qué es historicista? Porque en ella adquiere relevancia la temporalidad, la historicidad, el relativismo en nuestro teatro. El hecho teatral está incluido en el devenir socio-político, en el cual se producen las transformaciones. Aunque en forma limitada, se racionaliza el pasado y, trabajosamente, la producción teatral se visualiza dentro de un mercado de bienes culturales. En suma, se contextualizan nombre y hechos y se los relaciona con las circunstancias de producción.

En el trabajo de Ordaz, el hecho teatral, más que juzgado, es comprendido a partir de tres categorías fundamentales: su unicidad, su singularidad y su preteridad. Si bien no fundamenta su orientación estética, determina períodos o tendencias de acuerdo a una mínima ordenación sistemática previa. Está basada en hechos histórico-teatrales. La materia teatral es periodizada de acuerdo con sus propios caracteres ${ }^{4}$.

Su preocupación por el contexto supera el que demuestra por lo estrictamente literario y teatral. A pesar de este reparo, por primera vez en nuestra historiografía, encontramos en Ordaz un estudio del teatro popular. Aunque sin valorizarlo ni sistematizarlo, acertó a dar un lugar de importancia a un creador como Armando Discépolo, hoy "autor faro" de nuestra escena. Además, esclareció de manera profunda y ejemplar el desarrollo de nuestro teatro independiente.

El mayor mérito del texto de Ordaz, visto desde el momento histórico en que se dio a conocer, y lo que lo convierte en un maestro de nuestra historiografía teatral, es su sentido histórico, que lo lleva a ajustar las relaciones de pasado y presente y de presente mediato e inmediato de manera prospectiva. En la mayoría de los casos su actitud hacia el pasado es de comprensión no de juzgamiento. La excepción que podemos anotar es su postura frente al teatro comercial-popular de principios a mediados de siglo.

Desde nuestra perspectiva actual, el historicismo de hechos y nombres, aparece como superado. No obstante, creemos que sin los aportes de Ordaz, hubiera resultado imposible el resurgimiento de nuestra investigación teatral en la actualidad. Fue el primero que planteó la historia del teatro nacional como problema a resolver y sus descubrimientos son el origen de muchas de nuestras "certezas" presentes.

La historia de Berenguer Carisomo se complementa en sus falencias y aciertos con la de Ordaz, ya que incluye en su discurso un elemento que éste dejara casi totalmente de lado: una periodización que ubica cada momento de nuestra escena en su contexto estético, en la escuela literaria dominante. Es, como ya dijimos, una "historia de tendencias estéticas", que concreta a la manera de Marcelino Menéndez y Pelayo. Evidencia un intertexto ideológico muy marcado con los puntos de vista sostenidos por Ricardo Rojas, que en Berenguer Carisomo aparecen intensificados. Hay en su trabajo

\footnotetext{
${ }^{4}$ Esto es "Los orígenes", "Del picadero al escenario", "Los sainetes criollos", "La época de oro del Teatro Argentino", "El teatro por secciones", "La sociedad de autores", "Sigue la historia", "Otros autores", "Los teatros independientes", "Panorama final".
} 
una notoria voluntad de selección y de esclarecimiento, y un fino manejo crítico, intuitivo y también analítico.

Las limitaciones de sus resultados son varias: como en todos los casos mencionados anteriormente, la historia de Berenguer Carisomo se circunscribe a la literatura dramática; explica muy claramente los propósitos de su obra en la "Introducción" y el "Capítulo I", y cumple con ellos. Trazando lo que denomina "una historia espiritual de lo argentino", confunde lo tradicional con lo popular. Para Berenguer Carisomo, sólo de la tradición emergerá el verdadero teatro argentino, el cual, como la nacionalidad, aún está en pañales. Coincide con Menéndez y Pelayo en que para valorar la obra literaria o teatral no basta conocerla, sino que además hay que relacionarla con el "ambiente intelectual" de la época, con las ideas de su tiempo.

En el trabajo de Berenguer Carisomo encontramos un orientación general, una idea de proceso. Pero las insuficiencias que presenta el encadenamiento de causas y efectos, da como resultado una forma maniquea de observar el fenómeno teatral, ya que desde el comienzo se advierte que en su concepción aparecen dos clases de textos: los que son "reflejo" del teatro europeo, su mera continuidad, y las obras "emanadas del propio suelo, todavía imprecisas". Por "nuestro suelo" entiende la tradición hispano-criolla.

Cuestiona, por ejemplo, a Buenos Aires por haber "albergado gustosa" ese teatro "de reflejo", por haberse segregado de "de un tronco (el nacional) del que debió ser fruto y no raíz" (4).

El plan del libro se acoge a esta tesis y antítesis ${ }^{5}$. Sólo en el último capítulo, Berenguer Carisomo observa un síntesis, una fusión de la antinomia, al valorar la obras del realismo-naturalismo como el primer teatro adulto de nuestro país. Su libro presenta un mérito fundamental: no merodea los textos, penetra en ellos y, equivocado o no, nos da un punto de vista sobre ellos.

Estas historias son el emergente de una profunda transformación cultural del país, y sobre todo de su capital. La evolución de Buenos Aires como gran ciudad ocurrida dos décadas antes, se afirma en los años cuarenta, y la historización de nuestro teatro es un síntoma más de las tensiones entre modernidad europea y "diferencia" latinoamericana, entre lo finisecular y lo secular, entre criollismo y vanguardia. Cultura de mezcla, perceptible especialmente en la "Historia" de Ordaz. El campo intelectual se hallaba consolidado, con sus resortes de legitimación, su modelo general de producción y su "público educado" de clase media. Esta "comunidad interpretativa" tenía acceso al poder por medio de sus representantes, poseía su "biblioteca", sus gustos, formados en contacto con la cultura europea. Su reclamo ideológico era poseer una visión general de su evolución, que incluía, por supuesto, al teatro.

Por otra parte, el dinamismo social producido de 1944 a 1950 -años en que aparecen las "Historias" que nos ocupan- se intensifica con la aparición del peronismo (la historia de Berenguer Carisomo es un emergente de esa ideología). Hace su aparición un nuevo sector social en la vida nacional, una nueva manera de comprender el país y un irremediable antagonismo, que se percibe en los trabajos de Ordaz y Castagnino.

\footnotetext{
${ }^{5}$ La primera parte comprende cinco capítulos dedicados al teatro de la Colonia. La segunda, "La emancipación", consta de "El neoclasicismo jacobino", "Juan Cruz Varela", "Teatro popular de la época (1810-1835)". La tercera parte incluye bajo el título de "Argentina", desde la época de Rosas hasta 1948: "El siglo XIX, la estética", "Los Románticos", "El teatro del exilio", "El ciclo nativo" y "La fusión culta y popular", el teatro naturalista-realista de principios de siglo a 1918.
} 
De los cuarenta hasta el presente han pasado casi cincuenta años sin que se volviera a intentar en la Argentina una Historia del Teatro Nacional. Con el Grupo de Estudios de Teatro Argentino (GETEA) que funciona en el Área de Investigación de Teatro Argentino y Latinoamericano del Instituto de Arte Argentino y Latinoamericano de la Facultad de Filoso fía y Letras de la UBA, estamos dirigiendo un proyecto de historia, con un plantel de más de veinte investigadores. Esta es la primera peculiaridad de nuestro proyecto y es consecuencia de nuestra creencia de que es imposible para un solo investigador llevar adelante el objetivo planteado con la profundidad y amplitud que requiere la materia.

Nuestro modelo de periodización -que hemos descripto en otro trabajo más explícitamente (Pellettieri, 1991)-, investiga el teatro desde la perspectiva del cambio y la ruptura de sistemas teatrales, pero también los describe como continuidad, como entes de retención de manifestaciones teatrales. Pensamos la historia del teatro argentino como un proceso en el que lo sincrónico reflejado en la diacronía, juega un papel primordial en la descripción de textos dramáticos y espectaculares.

No indagamos fuentes, influencias, elementos exteriores al texto de los que el autor se vale para concretar la fábula. No creemos en las historias de teatro en las que un autor reemplaza a otro "por obra de su talento", ni en el advenimiento de cambios por "influencia" de un determinado autor norteamericano o europeo. Es evidente que en un planteo como el enunciado, el teatro argentino aparece sólo como una serie de influencias o bien librado a la "genialidad personal".

Por el contrario, hoy sabemos que la dramática y la puesta en escena argentina forman parte de un sistema teatral (Tinianov, 89-101; Guillén, 375-419; Villegas, 1984, 5-40; 1988, 179-203; Altamirano y Sarlo, 15-32), posee una densa textualidad, con sus propios modelos, que a partir de sus cambios e intentos de ruptura va evolucionando en el tiempo. Sus convenciones, su verosímil, tienen su propia legalidad, modulados por rclaciones con una comunidad de receptores. Su marcha está aclarada por su "historia interna" -la evolución de las formas-, pero sus cambios se explican por sus contactos con la serie social, especialmente por sus vínculos, sus aperturas a nuevos públicos.

Su correspondencia con otros sistemas, que podríamos denominar centrales (los europeos y el norteamericano), se concreta en su enlace con el "estímulo externo" (Golluscio de Montoya, 119-140). La modernización es el resultado de las relaciones con la serie social y el aporte del "estímulo externo" que logra intensificar y amplificar el movimiento propio de nuestro sistema teatral. En esta relación dialéctica que se establece entre el sistema teatral y las nuevas expectativas, exigencias y limitaciones de nuestro contexto social, mediatizadas por el campo intelectual, el "estímulo externo" sufre proceso de resemantización. Se disuelve en el sistema teatral y pasar a ser parte integrante del mismo.

Es por este motivo que consideramos nuestra metodología como "neohistoricista", ya que al estudio de los contextos sociales con los que trabaja el historicismo anterior, le incorporamos un trabajo sistemático sobre los textos que completa una visión más abarcadora.

Para nuestra concepción de la historia teatral, periodizar es determinar sistemas, aclarar su significación artística y social y relacionarlos con los anteriores y posteriores. Situarlos en la peculiaridad argentina y latinoamericana, admitir su multiplicidad. 
Advertir que en el sistema teatral argentino, en todas las épocas, coexistieron varios subsistemas $^{6}$, y que en cada uno de ellos coexistieron el culto o dominante ${ }^{7}$, con el residual $^{8}$ y el emergente ${ }^{9}$, en dialéctico y constante préstamo de procedimientos.

Sabemos, asimismo, que si todo texto es histórico y pertenece a su tiempo, nuestro discurso crítico comparte esa situación, que esta relativizado por nuestro lugar en la sociedad y en el campo intelectual y por su intencionalidad explícita e implícita.

Para la determinación de los períodos, tratamos de obviar, en la medida en que es posible, toda subjetividad. Trabajamos con un número considerable de textos dramáticos y teatrales, proyectando las distintas sincronías en el eje diacrónico. Para realizar el corte y para caracterizar las distintas fases de la Historia, obedecemos a la dialéctica interna inmanente en el sistema antes que a la organización por siglos, la adopción de nombre propios de la historia política o de los movimientos o corrientes literarias que no coinciden con los tiempos característicos de nuestro sistema teatral.

Intentamos apresar de manera racional la historia de los discursos teatrales en el lento transcurso de su constitución, su proceso de formación, su emancipación de los modelos europeos, en su no lineal logro de la identidad. Observamos también como se integra a una modernidad, como construye una cultura (Pellettieri, 1991).

Creemos que nuestro proyecto se incluye en el renacer de los estudios teatrales que tuvo lugar en la Argentina a partir de 1984, fecha en que comienzan a realizarse las Jornadas de Investigación Teatral de la Asociación de Críticos e Investigadores de Teatro de la Argentina (ACITA), posteriormente reemplazadas por las organizadas por AITEA, aparecen una serie de publicaciones sobre teatro nacional y latinoamericano y tienen lugar festivales como el de Córdoba, La movida del CELCIT entre otros.

Este renacer tiene, por supuesto, un correlato político en cl contexto social en el que nos movemos: la recuperación de la democracia en 1983. Sin duda la libertad, la apertura política, la autonomía y el debate universitarios, posibilitaron un clima en el cual pudimos nuevamente trabajar con "textos (que) pertenecen al mundo; que de algún modo, son hechos y que, aunque parezcan negarlo, son parte del mundo social, de la vida humana y del momento histórico en que se ubican e interpretan" (Said, 16).

En síntesis, los tres momentos pregnantes de la historiografía teatral argentina coinciden, en el caso de las primeras décadas del siglo, con la nacionalización de la

\footnotetext{
${ }^{6}$ Son divisiones internas dentro del sistema; cortes, cambios en los distintos niveles de texto (acción, procedimientos de la intriga, aspecto verbal y espectacular y recepción). También dentro de los subsistemas reconocemos microsistemas, manifestaciones peculiares de los distintos tipos de textos dramáticos y espectaculares.

${ }^{7}$ Según Williams (189-190), el sistema dominante es el que designa y legitima como literarios o teatrales determinado tipo de textos. Aclarando que: "En la producción cultural las condiciones de dominación están por lo general, claras en ciertas instituciones y formas dominantes. Estas pueden presentarse como desconectadas de las formas sociales dominantes, pero la eficacia de ambas depende de su profunda integración".

${ }^{s}$ Para Williams, la obra residual es la "realizada en sociedades y épocas anteriores y a menudo diferentes, pero todavía accesible y significativa" (190). Ampliando el concepto, podemos designar así al texto realizado contemporáneamente pero que se pliega a una ideología estética superada. Se identifica en Argentina y Latinoamérica con el subsistema popular.

' Siguiendo a Williams, son los textos emergentes, los nuevos, los que marcan un cambio dentro del sistema teatral: "Intentan avanzar (y a veces lo logran) más allá de las formas dominantes y de sus relaciones socioformales" (190).
} 
cultura; en la década del cuarenta con una fuerte modernización del campo intelectual y una democratización social muy amplia, y en la actualidad, con una democratización intensa y trabajosa, después de un largo período dictatorial. Sin que esta afirmación signifique la pretensión de establecer leyes, podríamos decir que los momentos de auge de nuestra disciplina coinciden hasta hoy con momentos de cambio o de fuertes crisis de crecimiento; con momentos de "verdad", de debate, que favorecen y posibilitan una. comunidad de intérpretes cuestionadora y cuestionada.

\section{A}

\section{RESUMO}

A crítica e a pesquisa teatral latino-americana foi severamente questionada. Obviamente, a crítica e a pesquisa teatral argentina não escapam a esse questionamento.

Neste trabalho, trataremos de três etapas de nossa historiografia teatral, centrando-nos especialmente nos trabalhos de Mariano G. Bosch (1865-1948), publicados entre 1904 e 1929 e que abragngem as três primeiras décadas do século, os de Ernesto Morales (1890-1959), Raúl H. Castagnino (1914-1998), Arturo Berenguer Carisomo (1905-1992) e Luiz Ordaz (1912), publicados na década de quarenta e, finalmente, à realização de uma História do Teatro Argentino que, sob nova direção, se está levando a cabo no GETEA, Área de Pesquisa Teatral do Instituto de História da Arte Argentina e Latino. americana da Faculdade de Filosofia e Letras da Universidade de Buenos Aires.

Em todos os casos, tratamos de esclarecer os pressupostos metodológicos dos quais partem os pesquisadores e indicar os seus sucessos e as dificuldades que a nosso parecer merecem, mas sem deixar de reconhecer a importância que tiveram, e ainda têm, tanto para o conhecimento do nosso teatro como pela contribuição que significa atualmente para os estudos sobre essa matéria.

PALAVRAS - CHAVE

historiografia teatral, teatro argentino

\section{BIBLIOGRAFIA}

Altamirano C. y B. Sarlo. Literatura y Sociedad. Buenos Aires: Hachette, 1982.

ARTACHo, Manuel. Noticias para la Historia del Teatro Nacional. Indice cronológico de Datos contenidos en la Historia del Teatro en Buenos Aires de M.G. Bosch. Buenos Aires: Ilar, 1940.

Berenguer Carisomo, Arturo. Las ideas estéticas en el teatro argentino. Buenos Aires, Instituto Nacional de Estudios de Teatro, 1947.

Bosch, Mariano G., Historia de los orígenes del Teatro Nacional Argentino y la época de Pablo Podestá. Buenos Aires: Solar/Hachette, 1969. Estudio preliminar Edmundo Guibourg. (Primera edición: Talleres L.J.Rosso, 1929) 
Bosch, Mariano G., Historia del teatro en Buenos Aires. Buenos Aires: El Comercio, 1910.

Bosch, Mariano G., Teatro antiguo en Buenos Aires. Piezas del siglo XVIII. Su influencia en la educación popular. Buenos Aires: El Comercio, 1904.

Castagnino, Raúl H., Esquema de la literatura dramática argentina (1917-1944). Buenos Aires: Instituto de Historia del Tcatro Americano, 1950. (Segunda edición: Literatura dramática argentina. Buenos Aires: Pleamar, 1968).

De Diego, Jacobo. Mariano G. Bosch, Talía, V, no 28, p. 6-7, enero 1966.

Golluscio De Montoya, E., Innovación dentro de la tradición escénica rioplatense: el caso Nemesio Trejo, Boletín del Instituto de Teatro, 4, p. 119.140, 1984.

Guilen, Claudio, Literature as system. Essays toward the Theory of Literary History. Princeton, N.Y.: Princeton University Press, 1971.

Morales, Ernesto. Historia del Teatro Argentino, Buenos Aircs: Lautaro, 1944.

Ordaz, Luis. El teatro en el Río de la Plata. Desde sus origenes hasta la actualidad. Buenos Aires: Futuro, 1946. 2ํe edición corregida y aumentada: Buenos Aires: Lcviatán, 1957.

Pelletifieri, O., Panorama de la década del diez, Testimonios culturales Argentinos. La década del 10. Buenos Aires: Editorial de Belgrano, 1980.

Pellettieri, O., Modelo de periodización del teatro argentino, Espacio de Critica e Investigación Teatral, 5, n²10, p 27-41, octubre 1991.

RojAs, Ricardo. Historia de la literatura argentina. Buenos Aires: G. Kraft, 1957.

SAID, E.W. Prólogo, The World, the Text and the Critic. Boston: Faber \& Faber, 1984.

Tinianov, J. Sobre la cvolución literaria", Teoría de la literatura de los formalistas rusos, T. Todorov (comp.) Buenos Aires: Signos, 1970.

Villegas, Juan. Teoría de historia literaria y poesía lírica. Ottawa: Girol Books, 1984.

VILlEgas, Juan. Ideología y discurso crítico sobre el teatro de España y América Latina. Minneapolis: The Prisma Institute Inc., 1988.

Williams, R. Sociología de la comunicación y del arte. Barcelona: Paidós, 1981. 